\title{
New vaccines for mammalian allergy using molecular approaches
}

\author{
Marianne van Hage ${ }^{1}$ and Gabrielle Pauli ${ }^{2}$ * \\ ${ }^{1}$ Clinical Immunology and Allergy Unit, Department of Medicine Solna, Karolinska Institutet and University Hospital, Stockholm, Sweden \\ ${ }^{2}$ Faculty of Medicine, Strasbourg University, Strasbourg, France
}

\author{
Edited by: \\ Christiane Hilger, Centre de \\ Recherche Public de la Santé, \\ Luxembourg \\ Reviewed by: \\ Mark Larché, McMaster University \\ Canada \\ Margarete Focke-Tejkl, Medical \\ University of Vienna, Austria \\ *Correspondence: \\ Gabrielle Pauli, Hôpitaux \\ Universitaires de Strasbourg, BP 426, \\ Strasbourg Cédex 67091, France \\ e-mail: gabrielle.pauli@ \\ chru-strasbourg.fr
}

\begin{abstract}
Allergen-specific immunotherapy (SIT) offers a disease specific causative treatment by modifying the allergen-specific immune response allowing tolerance to higher doses of allergen and preventing progression of allergic diseases. It may be considered in patients allergic to furry animals. Current mammalian allergy vaccines are still prepared from relatively poorly defined allergen extracts and may induce immediate and late phase side effects. Although the mechanisms of SIT are still not fully understood, the more recent approaches report different strategies to reduce both allergen-specific $\lg \mathrm{E}$ as well as $\mathrm{T}$ cell reactivity. The availability of recombinant allergens and synthetic peptides from the mammalian species has contributed to formulating new allergy vaccines to improve SIT for furry animal allergy. The majority of studies have focused on the major cat allergen Fel $\mathrm{d} 1 \mathrm{due}$ to its extensive characterization in terms of $\mathrm{IgE}$ and $\mathrm{T}$ cell epitopes and to its dominant role in cat allergy. Here we review the most recent approaches, e.g., synthetic peptides, recombinant allergen derivatives, different hypoallergenic molecules, and recombinant allergens coupled to virus-like particles or immunomodulatory substances as well as strategies targeting the allergen to Fc $\gamma$ receptors and the $\mathrm{MHC}$ class II pathway using a new route for administration. Many of the new vaccines hold promise but only a few of them have been investigated in clinical trials which will be the gold standard for evaluation of safety and efficacy in allergic patients.
\end{abstract}

Keywords: allergen-specific immunotherapy, Fel d 1, mammalian allergens, recombinant allergens, $\mathrm{T}$ cell peptides, vaccines

\section{INTRODUCTION}

Allergen-specific immunotherapy (SIT) offers a disease specific causative treatment by inducing tolerance to the allergen and preventing progression of allergic diseases, for example development of asthma (1). Hence, patients who suffer from allergies where avoidance is not possible such as house-dust mite respiratory allergies are the prime candidates for SIT. Allergy to cats, dogs, or other furry animals is common in society and the prevalence of sensitization to pets has increased (2). Although the best treatment is avoidance, it is often difficult to realize as well as not being well accepted by the patients. Moreover allergens from furry animals, e.g., the major cat allergen Fel $\mathrm{d} 1$ is equally present in houses without cats, in public places, public transport, day care centers, and school rooms. So the question of SIT may be considered. Allergen-specific immunotherapy for cat allergy has shown to be more favorable than for, e.g., dog allergy (3). This may depend on the standardization of cat extracts to Fel $\mathrm{d} 1$, whereas dog extracts may vary greatly in terms of allergen content (4).

The mechanisms of SIT are still not fully understood. The clinical efficacy is associated with the production of allergenspecific blocking immunoglobulin (Ig)G antibodies and the generation of $\mathrm{T}$ regulatory cell ( $\mathrm{T}$ regs) responses and secretion of immunoregulatory cytokines such as interleukin $10(5,6)$; however, current SIT involves drawbacks such as treatment persistence, due to the long treatment duration both with subcutaneous SIT and sublingual immunotherapy (7). Furthermore, SIT of today can induce adverse reactions ranging from mild symptoms to life-threatening anaphylaxis and even death (8).

Allergy vaccines of today are still made from crude allergen extracts, which are not well-defined. Since the structures of the most common allergen molecules are now available, well-defined recombinant and synthetic allergy vaccines can be generated allowing targeting specific mechanisms of allergic disease without increasing their allergenicity (9-11). Many of these new molecular approaches concern pollen allergens. It has been shown that SIT with the recombinant major birch allergen Bet $\mathrm{v} 1$ is equally effective as SIT with birch pollen extract or natural purified Bet v 1 (12). In this review, we describe different approaches for new vaccines, e.g., recombinant allergen derivatives, different hypoallergenic molecules, and recombinant allergens coupled to virus-like particles or to immunomodulatory substances. Studies being available concern principally evaluation of the cat major allergen, either in animal models or in allergic patients.

\section{GENERAL CONCEPTS TO INCREASE SAFETY OF ALLERGY VACCINES}

Side effects are related to the production of allergen-specific IgE antibodies but can also be mediated by the allergen-specific $T$ cells. Several studies during the last years have used an allergenunrelated carrier molecule, which provides $\mathrm{T}$ cell help for the 
production of IgG antibodies but avoid the activation of allergenspecific $\mathrm{T}$ cells. This approach would reduce $\mathrm{T}$ cell mediated side effects. Different strategies to reduce both $\operatorname{IgE}$ as well as allergenspecific $\mathrm{T}$ cell epitopes have been reported. These approaches will lead to less IgE and T cell-mediated side effects $(11,13)$.

- Strategies targeting allergen-specific $\mathrm{T}$ cells by using $\mathrm{T}$ cell epitope-containing peptides (synthetic molecules produced by chemical synthesis), which give no IgE-mediated activation of effector cells.

- Strategies reducing allergen-specific IgE reactivity, but conserving T cell reactivity.

- Strategies based on carrier-bound fusion proteins using peptides. These allergen derived peptides are obtained from the IgE-binding sites of the allergen but contain no or reduced allergen-specific $\mathrm{T}$ cell epitopes and exhibit no or strongly reduced IgE reactivity. The peptides are fused to an allergenunrelated viral carrier molecule and expressed as recombinant proteins. This technology was promoted by the Vienna group and a grass-pollen allergy vaccine based on carrier-bound peptides of the four major grass-pollen allergens is now under evaluation in a clinical phase II trial $(11,13-15)$.

Several other strategies for improving SIT have been described in the studies published within the last years: e.g., targeting the allergen to $\mathrm{Fc} \gamma$ receptors (16), targeting the MHC class II pathway (17), linking allergens to CpG-containing nucleotides $(18,19)$ or to carbohydrate-based particles (20), and co-administrating allergens with immunomodulatory substances such as vitamin D3
$(21,22)$. DNA vaccines favoring specific Th1 responses may also be used with different adjuvants such as CpG. mRNAs encoding allergens are another possible strategy, which would improve the safety of therapeutic nucleic acid-based vaccines. Moreover, different routes for SIT have been investigated using recombinant allergens especially sublingual, epicutaneous, and intra-lymphatic delivery of the allergen (23).

Table 1 provides a summary of these approaches that have been applied for furry animal allergen SIT. It is interesting to note that the majority of studies have focused on the major cat allergen Fel d 1 due to its dominant role in cat allergy and to its extensively characterization in terms of IgE and T cell epitopes.

\section{T CELL PEPTIDES}

$\mathrm{T}$ cell peptides were originally designed to modulate allergenspecific $\mathrm{T}$ cell responses without IgE-mediated activation of effector cells (35). Following preclinical studies (36), a series of clinical trials were performed to evaluate the safety and efficacy of two polypeptides from the major cat allergen Fel d 1. Initially, patients received a subcutaneous injection weekly for 4 weeks with an equimolecular mixture of the peptides (ALLERVAX CAT; Immunologic Pharmaceutical Corporation, Waltham, MA, USA, an equimolar combination of two 27-aminoacid synthetic peptides), 7.5, 75, and $750 \mu$ g, or placebo. Significant improvements in lung and nasal symptoms were observed in the high dose group but many adverse events occurred several hours after peptide injection (37). A subsequent multicenter study in which patients received eight injections of $750 \mu \mathrm{g}$ of vaccine reported only modest clinical improvement and immediate and late side effects were observed

Table 1 | Concepts and strategies for improving SIT for mammalian allergy.

\begin{tabular}{|c|c|c|c|}
\hline & Technologies & Specific approaches & Reference \\
\hline \multirow[t]{3}{*}{ Synthetic molecules } & Peptides & & \\
\hline & & Mixture of 12 short peptides & Oldfield et al. $(24)^{a}$ \\
\hline & & Mixture of 7 short peptides & Worm et al. $(25)^{a}$, Patel et al. (26) ${ }^{a}$ \\
\hline \multirow{7}{*}{$\begin{array}{l}\text { Recombinant } \\
\text { molecules }\end{array}$} & Hypoallergens & & \\
\hline & Mutants & Mus m 1 & Ferrari et al. (27) \\
\hline & Hybrids & $\begin{array}{l}\text { Fel d } 1 \text { duplicated T cell epitopes } \\
\text { and disruption of disulfide bounds }\end{array}$ & Saarne et al. (28) \\
\hline & Random mutation & Fel d 1 & Nilsson et al. (29) \\
\hline & Peptide carrier fusion proteins & & \\
\hline & Derived virus particles & Qß-Fel d 1 & Schmitz et al. (30) \\
\hline & Pre-S domain of hepatitis B & Fel d 1 peptides fused to Pre-S & Niespodziana et al. (31) \\
\hline \multirow{4}{*}{$\begin{array}{l}\text { Conjugation with } \\
\text { immunomodulatory } \\
\text { molecules }\end{array}$} & Fc $\gamma$ receptor & Truncated lgG Fc $\gamma$ Fel d 1 & Zhu et al. (16) \\
\hline & $\begin{array}{l}\text { Truncated invariant chain peptide }+ \\
\text { transactivator of transcription }\end{array}$ & MAT-Fel d 1 & Martinez-Gomez et al. (17), Senti et al. (32)a \\
\hline & Vitamin D3 & Fel d 1-Vitamin D3 & Jeffery et al. (33), Grundström et al. (22) \\
\hline & Carbohydrate-based particles & CBP-Fel d 1 & Neimert-Andersson et al. (20), Thunberg et al. (34) \\
\hline
\end{tabular}

MAT, modular antigen transporter; CBP, carbohydrate-based particle.

${ }^{a}$ Clinical studies. 
(38). Further developments using a mixture of 12 short peptides comprising the majority of the T cell epitopes from Fel $\mathrm{d} 1$ demonstrated that changes in the quality of life of the active treated group versus the placebo group, but isolated late asthmatic reactions were still observed (24). In a recent study, a new vaccine was developed consisting of a mixture of seven immunodominant peptides (ToleroMune cat ${ }^{\circledR}$, also known as cat PAD, Circassia Ltd, Oxford, UK), which were selected on the basis of MHC-binding characteristics. This approach allowed reducing the number of peptides without substantially compromising population coverage. The safety and tolerability of the vaccine was evaluated in a phase IIa study (25) where cat-allergic individuals were given a single dose of the vaccine either intradermally or subcutaneously. Inhibition of the late cutaneous reaction was considered as a surrogate of clinical efficacy and $3 \mathrm{nmol}$ was determined as the best concentration for intradermally desensitization. Treatment was performed in patients with cat-induced allergic rhinoconjunctivitis and in an environmental exposure chamber they were exposed to cat allergen before and after therapy. The clinical efficacy was observed after 18-22 weeks and 50-54 weeks after the start of the treatment and the highest dose of cat PAD $(6 \mathrm{nmol} 4$ weeks apart, compared to $3 \mathrm{nmol} 2$ weeks apart) gave the greatest efficacy. The treatment effect was apparent on nasal and ocular symptoms and persisted 9 months later without any further retreatment (26). Other clinical studies should confirm these encouraging results.

$\mathrm{T}$ cell peptides containing major allergen epitopes have been generated from the primary structures of other mammalian allergens such as Can f 1 (39), Bos d 2 (40), and Equ c 1 (41) but the potential application of these molecules in allergic patients have not been investigated.

\section{RECOMBINANT HYPOALLERGENIC DERIVATIVES}

Hypoallergenic derivatives are characterized by a strongly reduced IgE reactivity. The IgE-binding epitopes of Fel $\mathrm{d} 1$ have been modified through disruption of disulfide bonds and duplication of $\mathrm{T}$ cell epitopes. Three of the modified Fel d 1 derivatives displayed a strong reduction in allergenicity with 400-900 times lower IgEbinding capacity (hypoallergens) compared to wild-type Fel $\mathrm{d} 1$ (28). The therapeutic capacity of the hypoallergen with the most reduced IgE reactivity was evaluated in a mouse model for cat allergy and by skin tests on cat-allergic patients. An induction of Fel d 1-specific IgG antibodies with capacity of blocking patients' IgE to $\mathrm{rFel} \mathrm{d} 1$ and a reduction in airway responsiveness was noted. Furthermore, the hypoallergen showed a tendency of reduced SPT reactivity compared to $\mathrm{rFel} d$ in seven cat-allergic patients (42).

Other hypoallergenic mutants of rFel $\mathrm{d} 1$ have been generated by the introduction of random mutated allergen sequences and the selection of derivatives with a maintained tertiary structure by phage display using IgE antibodies from cat-allergic patients. The mutants had a lower IgE-binding and T cell activation capacity and could induce strong IgG-anti Fel d 1 protective responses by mouse immunization experiments. Thus they should be good candidates for safe alternatives for SIT (29).

Furthermore, in search of a vaccine for mouse allergy a structure-guided single point mutation has been performed for Mus $\mathrm{m} \mathrm{1}$, the major mouse allergen which is an urinary protein. This mutation induced a spatial rearrangement of aromatic side chains and a lower allergenic activity although the $\mathrm{T}$ cell reactivity was preserved (27).

\section{PEPTIDE CARRIER FUSION PROTEINS}

One strategy to improve SIT has been to couple allergens to the bacteriophage Q $ß$-derived virus-like particles. In mice, one injection of QB coupled to Fel d 1 induced a Fel d 1-specific IgG response, and reduced anaphylactic reactions after $\mathrm{rFel} d$ challenge (30). However, the chemical coupling process might be difficult to standardize for vaccine production.

Another carrier protein, the Pre-S domain of hepatitis B virus has been evaluated more recently (31). The cat hypoallergen vaccine was produced by fusion of Pre-S of hepatitis B to two non-allergenic Fel d 1 derived peptides. This approach has shown to eliminate both IgE-mediated and T cell mediated side effects. The $\mathrm{T}$ cell help comes from a Fel d 1-unrelated carrier protein, the Pre-S domain of hepatitis B virus, which contains antigenic sites for both B and T cells (43). The recombinant fusion protein exhibited more than 1000-fold reduction in allergenic activity compared with rFel d 1 (31). After immunization of mice and rabbits the fusion protein induced Fel d 1-specific IgG antibodies, which inhibited IgE-binding of cat-allergic patients to Fel d 1. In addition, the $\mathrm{T}$ cell responses in immunized mice were specific for Pre-S and very low for Fel d 1 . This vaccine has to be further evaluated in clinical studies to confirm its promising qualities.

\section{CONJUGATION TO MOLECULES WITH IMMUNOMODULATORY FUNCTIONS}

A chimeric human-cat fusion protein composed of a truncated human IgG Fc gamma 1 and Fel d 1 has been proposed for a new approach of SIT (16). This conjugate induced a dose dependent inhibition of Fel d 1 driven IgE histamine release from cat-allergic donors' basophiles and from sensitized human cord-blood derived mast cells. The vaccine potential was also demonstrated in a mouse model for cat allergy $(16,44)$.

A new technology called modular antigen translocation (MAT) has been applied to Fel $\mathrm{d} 1$ to enhance immunogenicity and safety of SIT. By attaching a truncated invariant chain peptide, and a transactivator of transcription peptide to allergens, they are converted into cytoplasmic proteins targeting the MHC class II pathway (17). MAT fusion of rFel d 1 has shown to enhance protective antibody and Th1 responses in mice, while reducing human basophil degranulation (17). A recent paper has described a phase I/IIa, randomized, placebo-controlled, and double-blind trial, using this construct by intra-lymphatic injections in cat dander allergic patients (20 patients were randomized) (32). The intralymphatic route has shown to reduce both the number of allergen injections as well as the allergen dose, improving both efficacy and safety of SIT (45). Three monthly injections with increasing doses of MAT-Fel d 1 elicited no adverse events and there was significant increase in allergen tolerance after nasal provocation. Regulatory $\mathrm{T}$ cell responses were stimulated and IL10 cytokine secretion and increased cat dander specific IgG4 production were observed. This clinical study represents the first immunotherapy trial with a recombinant cat allergen. It is also a major improvement over classical immunotherapy due to improved safety, low allergen doses, few injections, and a short treatment period. This 
promising vaccination approach has to be confirmed in larger patient studies and also by assessing efficacy on reduction of symptoms and medication use and long term follow-up.

1,25-Dihydrovitamin D3 has been shown to induce dendritic cells with tolerogenic properties, thus, increasing regulatory $\mathrm{T}$ cell responses (33). In an attempt to use this effect, VD3 was covalently coupled to rFel d 1 and tested in a mouse model for cat allergy (22). $\mathrm{rFel} \mathrm{d} 1 \mathrm{VD} 3$ was superior to $\mathrm{rFel} \mathrm{d} 1$ in reducing airway inflammation, and airway hyperresponsiveness, and in producing allergen-specific IgG blocking antibodies.

rFel 1 has also been covalently coupled to carbohydrate-based particles (CBP) for targeting of dendritic cells and enhanced adjuvanticity in SIT (34). This approach was evaluated in a mouse model for cat allergy (20). CBP-rFel d 1 treated mice showed reduced features of allergic inflammation and increased allergenspecific IgM and IgG responses. In a prophylactic protocol it was also shown that $\mathrm{CPB} \mathrm{rFel} \mathrm{d} 1$ prevents the induction of airway inflammation possibly through the induction of allergenspecific IgG and IgM and by a prolonged tissue exposure to rFel d 1 (34).

\section{CONCLUSION}

Better characterization of recombinant allergens from mammalian species has contributed to formulate new allergy vaccines to improve SIT for patients allergic to furry animals. The identification of the major allergens in allergen sources is essential for generating vaccines, which may replace the natural allergen extract $(11,46)$. This explains in part why a majority of the new furry animal allergy vaccines have been restricted to the major cat allergen Feld 1. Further studies are needed to point out which allergen component/s are needed for treatment of furry animal allergy, taking in account the great variability of commercial extracts regarding their allergen contents. This is especially true for dog allergens (4) where the panel of allergens so far is incomplete. Several studies presented here explore new concepts for improving the safety of SIT, by using different approaches and various technologies. However, only a few of them have been investigated in clinical trials, which will be the gold standard for evaluation of safety and efficacy in allergic patients.

\section{ACKNOWLEDGMENTS}

Supported by the Swedish Research Council, the Stockholm County Council, the Swedish Asthma and Allergy Association's Research Foundation, the King Gustaf V 80th Birthday Foundation, the Swedish Heart-Lung Foundation, the Hesselman Foundation, the Konsul Th C Bergh Foundation, the Center for Inflammatory Diseases, the Swedish Cancer and Allergy Foundation and Karolinska Institutet.

\section{REFERENCES}

1. Jacobsen L, Niggeman B, Dreborg S, Ferdousi HA, Halken S, Koivikko A, et al. Specific immunotherapy has long-term preventive effect of seasonal and perennial asthma: 10 year follow-up on the PAT study. Allergy (2007) 62:943-8. doi:10.1111/j.1398-9995.2007.01451.x

2. Wickman M, Asarnoj A, Tillander H, Andersson N, Bergström A, Kull I, et al. Childhood-to-adolescence evolution of IgE antibodies to pollens and plant foods in the BAMSE cohort. J Allergy Clin Immunol (2014) 133:580-2.e8. doi:10.1016/j.jaci.2013.09.009
3. Hedlin G, Graff-Lonnevig V, Heilborn H, Lilja G, Norrlind K, Pegelow K, et al. Immunotherapy with cat- and dog-dander extracts. V. Effects of 3 years of treatment. J Allergy Clin Immunol (1991) 87:955-64. doi:10.1016/0091-6749(91) 90417-M

4. Curin M, Reininger R, Swoboda I, Focke M, Valenta R, Spitzauer S. Skin prick test extracts for dog allergy diagnosis show considerable variations regarding the content of major and minor dog allergens. Int Arch Allergy Immunol (2011) 154:258-63. doi:10.1159/000321113

5. Nouri-Aria KT, Wachholz PA, Francis JN, Jacobson MR, Walker SM, Wilcock LK, et al. Grass pollen immunotherapy induces mucosal and peripheral IL-10 responses and blocking IgG activity. J Immunol (2004) 172:3252-9.

6. Pipet A, Botturi K, Pinot D, Vervloet D, Magnan A. Allergen-specific immunotherapy in allergic rhinitis and asthma. Mechanisms and proof of efficacy. Respir Med (2009) 103:800-12. doi:10.1016/j.rmed.2009.01.008

7. Kiel MA, Röder E, van Wijk RG, Al MJ, Hop WC, Rutten-van Mölken MP. Real-life compliance and persistence among users of subcutaneous and sublingual allergen immunotherapy. J Allergy Clin Immunol (2013) 132:353-60. doi:10.1016/j.jaci.2013.03.013

8. Burks AW, Calderon MA, Casale T, Cox L, Demoly P, Jutel M, et al. Update on allergy immunotherapy: American Academy of Allergy, Asthma \& Immunology/European Academy of Allergy and Clinical Immunology/PRACTALL consensus report. JAllergy Clin Immunol (2013) 131:1288.e-96.e. doi:10.1016/j.jaci. 2013.01.049

9. Valenta R, Ferreira F, Focke-Tejkl M, Linhart B, Nieberberger V, Swoboda I, et al. From allergen genes to allergy vaccines. Annu Rev Immunol (2010) 28:211-41. doi:10.1146/annurev-immunol-030409-101218

10. Thomas WR. The advent of recombinant allergens and allergen cloning. J Allergy Clin Immunol (2011) 127:855-9. doi:10.1016/j.jaci.2010.12.1084

11. Valenta R, Campana R, Marth K, van Hage M. Allergen-specific immunotherapy: from therapeutic vaccines to prophylactic approaches. J Intern Med (2012) 272:144-57. doi:10.1111/j.1365-2796.2012.02556.x

12. Pauli G, Larsen TH, Rak SZ, Horak F, Pastorello E, Valenta R, et al. Efficacy of recombinant birch pollen vaccine for the treatment of birch-allergic rhinoconjunctivitis. J Allergy Clin Immunol (2008) 122:951-60. doi:10.1016/j.jaci.2008. 09.017

13. Focke-Tejkl M,Valenta R. Safety of engineered allergen-specific immunotherapy vaccines. Curr Opin Allergy Clin Immunol (2012) 12:556-63. doi:10.1097/ACI. 0b013e328357ca53

14. Focke M, Swoboda I, Marth K, Valenta R. Developments in allergen-specific immunotherapy: from allergen extracts to allergy vaccines bypassing allergenspecific immunoglobulin E and T cell reactivity. Clin Exp Allergy (2010) 40(3):385-97. doi:10.1111/j.1365-2222.2009.03443.x

15. Marth K, Breyer I, Focke-Tejkl M, Blatt K, Shamji MH, Layhadi J, et al. A nonallergenic birch pollen allergy vaccine consisting of hepatitis PreS-fused Bet v 1 peptides focuses blocking IgG toward IgE epitopes and shifts immune responses to a tolerogenic and Th1 phenotype. J Immunol (2013) 190:3068-78. doi:10.4049/jimmunol.1202441

16. Zhu D, Kepley CL, Zhang K, Terada T, Yamada T, Saxon A. A chimeric human-cat fusion protein blocks cat-induced allergy. Nat Med (2005) 11:446-9. doi: $10.1038 / \mathrm{nm} 1219$

17. Martinez-Gomez JM, Johansen P, Rose H, Steiner M, Senti G, Rhyner C, et al. Targeting the MHC class II pathway of antigen presentation enhances immunogenicity and safety of allergen immunotherapy. Allergy (2009) 64:172-8. doi:10.1111/j.1398-9995.2008.01812.x

18. Santeliz JV, Van Nest G, Traquina P, Larsen E, Wills-Karp M. Amb a 1-linked $\mathrm{CpG}$ oligo-deoxynucleotides reverse established airway hyperresponsiveness in a murine model of asthma. J Allergy Clin Immunol (2002) 109:455-62. doi:10.1067/mai.2002.122156

19. Tulic MK, Fiset PO, Christodoulopoulos P, Vaillancourt P, Desrosiers M, Lavigne F, et al. Amb a 1-immunostimulatory oligodeoxynucleotide conjugate immunotherapy decreases the nasal inflammatory response. J Allergy Clin Immunol (2004) 113:235-41. doi:10.1016/j.jaci.2003.11.001

20. Neimert-Andersson T, Thunberg S, Swendin L, Wiedermann U, JacobssonEkman G, Dahlen SE, et al. Carbohydrate-based particles reduce allergic inflammation in a mouse model for cat allergy. Allergy (2008) 53:518-26. doi:10.1111/ j.1398-9995.2008.01644.x

21. Taher YA, van Esch BC, Hofman GA, Henricks PA, van Oosterhout A. lalpha,25-dihydroxyvitamin D3 potentiates the beneficial effects of allergen 
immunotherapy in a mouse model of allergic asthma: role for IL-10 and TGF-B. J Immunol (2008) 180:5211-21.

22. Grundström J, Neimert-Andersson T, Kemi C, Nilsson OB, Saarne T, Andersson $\mathrm{M}$, et al. Covalent coupling of vitamin D3 to the major cat allergen Fel d 1 improves the effects of allergen-specific immunotherapy in a mouse model for cat allergy. Int Arch Allergy Immunol (2012) 157:136-46. doi:10.1159/000327546

23. Johansen P, von Moos S, Mohanan D, Kündig TM, Senti G. New routes for allergen immunotherapy. Hum Vaccin Immunother (2012) 8:1525-33. doi:10.4161/hv.21948

24. Oldfield WL, Larché M, Kay AB. Effect of T-cell peptides derived from Fel d 1 on allergic reactions and cytokine production in patients sensitive to cats: a randomised controlled trial. Lancet (2002) 360:47-53. doi:10.1016/S01406736(02)09332-7

25. Worm M, Lee HH, Kleine-Tebbe J, Hafner RP, Laidler P, Healey D, et al. Development and preliminary clinical evaluation of a peptide immunotherapy vaccine for cat allergy. J Allergy Clin Immunol (2011) 127:89-97. doi:10.1016/j.jaci.2010. 11.029

26. Patel D, Couroux P, Hickey P, Salapatek AM, Laidler P, Larché M, et al. Fel d 1-derived peptide antigen desensitization shows a persistent treatment effect 1 year after the start of dosing: a randomized, placebo-controlled study. J Allergy Clin Immunol (2013) 131:103-9. doi:10.1016/j.jaci.2012.07.028

27. Ferrari E, Breda D, Longhi R, Vangelista L, Nakaie CR, Elviri L, et al. In search of a vaccine for mouse allergy: significant reduction of Mus $\mathrm{m} 1$ allergenicity by structure-guided single-point mutations. Int Arch Allergy Immunol (2012) 157:226-37. doi:10.1159/000327551

28. Saarne T, Kaiser L, Grönlund H, Rasool O, Gafvelin G, van Hage-Hamsten M. Rational design of hypoallergens applied to the major cat allergen Fel d 1. Clin Exp Allergy (2005) 35:657-63. doi:10.1111/j.1365-2222.2005.02234.x

29. Nilsson OB, Adedoyin J, Rhyner C, Neimert-Andersson T, Grundström J, Berndt $\mathrm{KD}$, et al. In vitro evolution of allergy vaccine candidates, with maintained structure, but reduced B cell and T cell activation capacity. PLoS One (2011) 6:e24558. doi:10.1371/journal.pone.0024558

30. Schmitz N, Dietmeier K, Bauer M, Maudrich M, Utzinger S, Muntwiler S, et al. Displaying Fel d 1 on virus-like particles prevents reactogenicity despite greatly enhanced immunogenicity: a novel therapy for cat allergy. J Exp Med (2009) 206:1941-55. doi:10.1084/jem.20090199

31. Niespodziana K, Focke-Tejkl M, Linhart B, Civaj V, Blatt K, Valent PM, et al. A hypoallergenic cat vaccine based on Fel d 1-derived peptides fused to hepatitis B PreS. J Allergy Clin Immunol (2011) 127:1562-70. doi:10.1016/j.jaci. 2011.02.004

32. Senti G, Crameri R, Kuster D, Johansen P, Martinez-Gomez JM, Graf N, et al. Intralymphatic immunotherapy for cat allergy induces tolerance after only 3 injections. J Allergy Clin Immunol (2012) 129:1290-6. doi:10.1016/j.jaci.2012. 02.026

33. Jeffery LE, Burke F, Mura M, Zheng Y, Qureshi OS, Hewison M, et al. 1,25-Dihydroxyvitamin D3 an IL-2 combine to inhibit $\mathrm{T}$ cell production of inflammatory cytokines and promote development of regulatory $\mathrm{T}$ cells expressing CTLA-4 and FoxP3. J Immunol (2009) 183:5458-67. doi:10.4049/jimmunol. 0803217

34. Thunberg S, Neimert-Andersson T, Cheng Q, Wermeling F, Bergström U, Swedin L, et al. Prolonged antigen-exposure with carbohydrate particle based vaccination prevents allergic immune responses in sensitized mice. Allergy (2009) 64:919-26. doi:10.1111/j.1398-9995.2008.01905.x

35. Moldaver D, Larché M. Immunotherapy with peptides. Allergy (2011) 66:784-91. doi:10.1111/j.1398-9995.2011.02610.x
36. Briner TJ, Kuo MC, Keating KM, Rogers BL, Greenstein JL. Peripheral T-cell tolerance induced in naïve and primed mice by subcutaneous injection of peptides from the major cat allergen Fel d 1. Proc Natl Acad Sci U S A (1993) 90:7608-12. doi:10.1073/pnas.90.16.7608

37. Norman PS, Ohman JL, Long AA, Creticos PS, Gefter MA, Shaked Z, et al. Treatment of cat allergy with T-cell reactive peptides. Am J Respir Crit Care Med (1996) 154:1623-8. doi:10.1164/ajrccm.154.6.8970345

38. Maguire P, Nicodemus C, Robinson D, Aaronson D, Umetsu DT. The safety and efficacy of ALLERVAX CAT in cat allergic patients. Clin Immunol (1999) 93:222-31. doi:10.1006/clim.1999.4795

39. Immonen A, Farci S, Taivainen A, Partanen J, Pouvelle-Moratille S, Närvänen A, et al. $\mathrm{T}$ cell epitope-containing peptides of the major dog allergen Can $\mathrm{f} 1$ as candidates for allergen immunotherapy. J Immunol (2005) 15(175):3614-20.

40. Kinnunen T, Jutila K, Kwok WW, Rytkönen-Nissinen M, Immonen A, Saarelainen S, et al. Potential of an altered peptide ligand of lipocalin allergen Bos d 2 for peptide immunotherapy. J Allergy Clin Immunol (2007) 119:965-72. doi:10.1016/j.jaci.2007.01.011

41. Immonen A, Kinnunen T, Sirven P, Taivainen A, Houitte D, Peräsaari J, et al. The major horse allergen Equ $\mathrm{c} 1$ contains one immunodominant region for $\mathrm{T}$ cell epitopes. Clin Exp Allergy (2007) 37:939-47. doi:10.1111/j.1365-2222.2007. 02722.x

42. Saarne T, Neimert-Andersson T, Grönlund H, Jutel M, Gafvelin G, van Hage $\mathrm{M}$. Treatment with a Fel $\mathrm{d} 1$ hypoallergen reduces allergic responses in a mouse model for cat allergy. Allergy (2011) 66:255-63. doi:10.1111/j.1398-9995.2010. 02468.x

43. Milich DR. T- and B-cell recognition of hepatitis B viral antigens. Immunol Today (1988) 9:380-6. doi:10.1016/0167-5699(88)91239-X

44. Terada T, Zhang K, Belperio J, Londhe V, Saxon A. A chimeric human-cat Fcgamma-Fel d 1 fusion protein inhibits systemic, pulmonary, and cutaneous allergic reactivity to intratracheal challenge in mice sensitized to Fel $\mathrm{d} 1$, the major cat allergen. Clin Immunol (2006) 120:45-56. doi:10.1016/j.clim.2005.12.010

45. Martínez-Gómez JM, Johansen P, Erdmann I, Senti G, Crameri R, Kündig TM. Intralymphatic injections as a new administration route for allergen-specific immunotherapy. Int Arch Allergy Immunol (2009) 150(1):59-65. doi:10.1159/ 000210381

46. Nilsson OB, van Hage M, Gronlund H. Mammalian-derived respiratory allergens - implications for diagnosis and therapy of individuals allergic to furry animals. Methods (2014) 66:86-95. doi:10.1016/j.ymeth.2013.09.002

Conflict of Interest Statement: The authors declare that the research was conducted in the absence of any commercial or financial relationships that could be construed as a potential conflict of interest.

Received: 11 November 2013; accepted: 14 February 2014; published online: 14 March 2014.

Citation: van Hage M and Pauli G (2014) New vaccines for mammalian allergy using molecular approaches. Front. Immunol. 5:81. doi: 10.3389/fimmu.2014.00081

This article was submitted to Immunotherapies and Vaccines, a section of the journal Frontiers in Immunology.

Copyright $\odot 2014$ van Hage and Pauli. This is an open-access article distributed under the terms of the Creative Commons Attribution License (CC BY). The use, distribution or reproduction in other forums is permitted, provided the original author(s) or licensor are credited and that the original publication in this journal is cited, in accordance with accepted academic practice. No use, distribution or reproduction is permitted which does not comply with these terms. 